\title{
Control of Battery Energy Storage System for Wind Turbine based on DFIG during Symmetrical Grid Fault
}

\author{
T. Riouch ${ }^{1,2}$, R. EL-Bachtiri ${ }^{2}$, A. Alamery ${ }^{1}$ and C. Nichita ${ }^{1}$ \\ ${ }^{1}$ Groupe de Recherche en Electrotechnique et Automatique \\ GREAH Laboratory, University of Le Havre \\ Le Havre, France \\ e-mail: tariq.riouch@gmail.com, ahamedsaad@yahoo.com, nichita@univ-lehavre.fr \\ ${ }^{2}$ LESSI laboratory, FSDM USMBA University REEPER Group, EST-Fez, BP 2427, Fez MOROCCO \\ e-mail: $\underline{\text { bachtiri@yahoo.fr }}$
}

\begin{abstract}
This paper presents a specific control strategy of Doubly Fed Induction Generator (DFIG) conceived for a wind turbine system operating under electrical grid disturbance. Two mains aspects related to DFIG behavior are studied: fluctuation of its output power and Low-Voltage Ride Trough capability (LVRT) of wind turbine generator system. In order to smooth the output power injected in the electrical grid and to improve dynamic behavior of a variable speed wind turbine generator system under symmetrical voltage dip, a control strategy of the Battery Energy Storage System (BESS) is proposed. Simulations have been carried out in Matlab environment, and the results validate the effectiveness of our control.
\end{abstract}

\section{Key words}

Doubly Fed Induction Generator, Low Voltage Ride Through, DC link voltage, electrical grid fault.

\section{Introduction}

Wind energy is one of the most renewable energy resources used to deal with the environmental degradation due to $\mathrm{CO} 2$ emissions from traditional power plants. The doubly fed induction generator (DFIG) shown in Figure 1 is the most used in generating wind power exceeding $1 \mathrm{MW}$, thanks to these advantages: operation with variable speeds, decoupled control of active and reactive power, reliability and robustness. In addition the power converters which manages only the slip energy can be sized between $25 \%-30 \%$ of the nominal power of the DFIG [1],[2].

Several classical controls strategies are used to control DFIGs: direct torque control (DTC), direct power control (DPC), and vector control (VC) [3]. Considering the vector control, the stator winding of the DFIG is directly connected to the grid, the rotor winding are connected to the grid via two converters; rotor side converter (RSC) and grid side converter (GSC). These two converters are connected together via a DC bus. The RSC is generally used for controlling the decoupled active power (or torque). This converter receives the reference speed calculated in the wind turbine control unit as an optimized value using the wind speed $V_{\omega}$. In the same time this control unit calculates the blade angle $\beta$. The RSC receives also the reactive power reference $Q_{s}^{*}$, the rotor current $i_{r}$ and line voltage $U_{s}$ to enable the vector control of DFIG.

Reactive power (or flux), and the GSC for stabilizing the DC bus voltage and to control the reactive power injected by GSC into grid.

Increasing numbers of wind farms and their penetration in power systems have led researchers to focus on studies of grid electrical which contain wind power plants and the establishment of grid codes for wind connections to the grid electrical [1],[2].

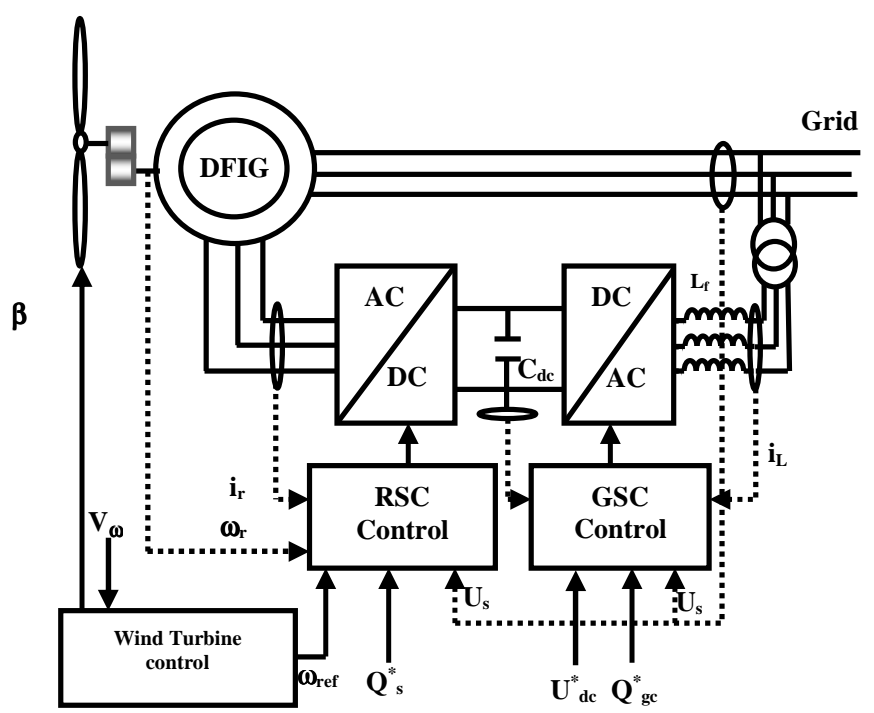

Fig.1.Configuration of a DFIG wind turbine system

The DFIG is facing two major problems; first the stator of the DFIG is directly connected to the grid; this makes 
the DFIG very sensitive to the grid disturbances. When the grid is affected by a fault, the voltage at the point of common coupling will drop causing an over-current in the stator windings. Magnetic coupling between the stator and the rotor will induce an overvoltage in rotor windings with an over-current in the rotor. This may cause the destruction of the rotor side converter and cause a voltage fluctuation of the DC bus [4],[5].

The second problem is output power fluctuation, despite of advanced control strategy applied to DFIG, the power injected by the Wind Turbine varies with the variation of the wind velocity [6].

With the continuity of the increased penetration of wind power in electric power systems, system operators have revised their codes on the connection of wind farms to power grids and fault ride-through capability.

Currently, different codes require that wind turbines should remain connected to the grid during the fault (e.g. voltage sag); figure 2 shows the fault-ride trough requirement of the voltage dip in different countries.

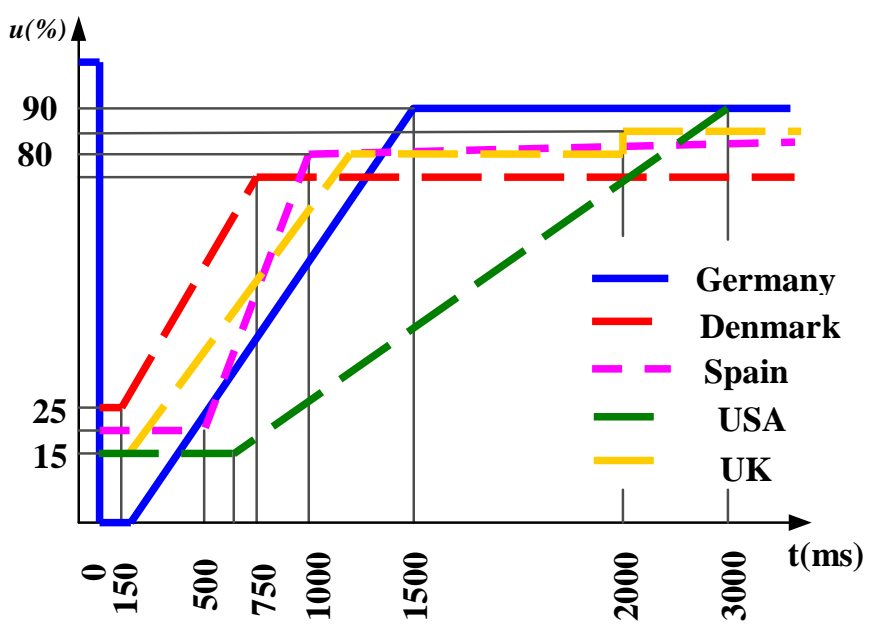

Fig.2 Different requirements in grid codes.

The wind turbines shall remain connected during faults for a voltage profile as shown in Fig. 2, If we take the case of Germany The wind power plants are required to stop drawing the reactive power and to be able to inject reactive power within $1500 \mathrm{msec}$ of grid recovery. If the voltage on the low voltage side of each individual generator transformer falls and remains at and below 80\%, the generators must disconnect themselves from the grid after $1.5 \mathrm{sec}$.

Much research has been done to keep the DFIG wind turbine connected to the grid and to protect converters in case of symmetrical faults of the electrical grid. In [7] a method for uninterrupted operation of the DFIG during faults has been proposed. In this structure the rotor side converter is blocked and the rotor winding of DFIG were short-circuited via a crow-bar, the DFIG becomes as conventional induction generator, it absorbs reactive power network and injects active power to the electrical grid. The dynamic VAr compensators are used in DFIG wind turbine systems terminals to provide the necessary reactive power during a grid fault [1]. A novel control strategy for smoothing the output power of DFIG and protect the power converter has been presented in [8]. In [9] and [10] a DC chopper is used to limit overcharge during low grid voltage. A battery energy storage system
(BESS) is used to absorb or inject the power for smoothing the power fluctuations due to the variation of the wind speed and the excess of power transfer to the DC bus via the RSC during the fault [11]-[12]-[16].

In this paper, an advanced control is proposed in order to keep the DFIG connected to electrical grid. Particularities of the proposed control are the reduction of the overcurrents in winding rotor and reduction the overshot in DC bus voltage, ensuring the protection of the DC bus and power converters.

The organization of this paper is as follows: firstly the DFIG under symmetrical fault are studied. Then, the proposed control is presented. Finally, simulation results developed in Matlab/Simulink are presented; an analysis and a comparison between the conventional control and the proposed control are effectuated.

\section{DFIG under grid fault}

\section{A. DFIG Model}

The model generally used for the DFIG is the Park's model [9]. For the simplification of the study, the rotor variables will be referred to as the stator:

$$
\begin{aligned}
& \vec{v}_{s}=R_{s} \cdot \vec{i}_{s}+\frac{d}{d t} \vec{\psi}_{s} \\
& \vec{v}_{r}=R_{r} \vec{i}_{r}+\frac{d}{d t} \vec{\psi}_{r}-j \omega \vec{\psi}_{s}
\end{aligned}
$$

Where $i$ represents the current, $v$ the voltage, $\psi$ the magnetic flux, $\omega$ the rotor electrical speed and $R$ the resistance. The subscripts $r$ and $s$ indicate rotor and stator variables.

In the case of DFIG, the stator windings are directly connected to the grid, which means that the stator voltage $v_{s}$ is determined by the grid. The rotor voltage $v_{r}$ is controlled by rotor side converter and used to perform the machine control. The stator and rotor fluxes are given by:

$$
\begin{aligned}
& \vec{\psi}_{s}=L_{s} \overrightarrow{i_{s}}+L_{m} \overrightarrow{i_{r}} \\
& \vec{\psi}_{r}=L_{r} \overrightarrow{i_{r}}+L_{m} \overrightarrow{i_{s}}
\end{aligned}
$$

Where $L_{m}$ represents the magnetizing inductance, $L_{s}$ and $L_{r}$ represents the stator and rotor inductance, respectively. The rotor voltage is one of the most important variables for the converter. This voltage is induced by the variation of the rotor flux, which can be calculated from (3) and (4):

$$
\vec{\psi}_{r}=\frac{L_{m}}{L_{s}} \vec{\psi}_{s}+\sigma L_{r} \cdot \vec{i}_{r}, \quad \sigma=1-\frac{L_{m}{ }^{2}}{L_{s} L_{r}}(5)
$$

$\sigma$ being the leakage factor and $\sigma L_{r}$ the rotor transient inductance.

From (2) and (5), the following expression is obtained:

$$
\vec{v}_{r}=\frac{L_{m}}{L_{s}} \frac{d \vec{\psi}_{s}^{r}}{d t}-\left(R_{r} \vec{i}_{r}+\sigma L_{r} \frac{d \vec{i}_{r}}{d t}\right)
$$

The rotor voltage given by (6) can be divided into two items. The first will be referred to as EMF it is induced by the stator flux and the second item is the voltage drop caused by the rotor current in both rotor transient inductance $\sigma L_{r}$ and the rotor resistance $R_{r}$. 


\section{B. Behaviour under Grid Fault}

During normal operation, neglecting the stator resistance Rs, the stator flux linkage can be expressed as [13],[14].

$$
\vec{\psi}_{s}^{s}=\frac{V_{s}}{j \omega_{s}} e^{j \omega_{s} t}
$$

Where $\omega s$ is the stator angular frequency, $\mathrm{Vs}$ is the amplitude of stator voltage. Then the EMF induced by the stator flux linkage during normal condition can be calculated according to (6)

$$
\vec{e}_{r}=\frac{L_{m}}{L_{s}} \frac{d}{d t} \vec{\psi}_{s}^{r}=\frac{L_{m}}{L_{s}} s V_{s} e^{j \omega_{s t}}
$$

Where $s$ is the slip, and $\omega_{s r}$ is slip angular frequency. The amplitude of the EMF $e_{r}$ is $s V_{s} L_{m} / L s$, which is proportional to the slip $s$. Typically, $s$ is variable between -0.3 and 0.3 , so the EMF under normal condition is relatively small.

Under symmetrical fault occurs, the stator flux linkage would contain DC component, and can be expressed as [14],[15].

$$
\vec{\psi}_{s}^{s}=\frac{V_{s}(1-p)}{j \omega_{s}} e^{j \omega_{s} t}+\frac{V_{s} p}{j \omega_{s}} e^{\frac{-t}{\tau_{s}}}
$$

Where $p$ is the depth of voltage dip, and $\tau_{s}$ is the time constant of the stator flux linkage. The first item is the positive sequence component of the stator flux linkage, and the second item is the DC component, which decays with the time constant $\tau_{s}$. Then according to (6), the EMF under symmetrical faults can be given by:

$$
\vec{e}_{r}=\frac{L_{m}}{L_{s}}\left[s V s(1-p) e^{j \omega_{s r} t}-V_{s} p(1-s) e^{-j \omega_{r} t} e^{\frac{-t}{\tau_{s}}}\right]
$$

\section{Proposed control}

A schematic diagram of the DFIG with proposed control is shown in figure 3 . The proposed scheme consists of a rotor side ac/dc converter (RSC), a dc link capacitor with Battery Energy Storage System (BESS), and a grid side dc/ac converter (GSC), as shown in Fig. 3.

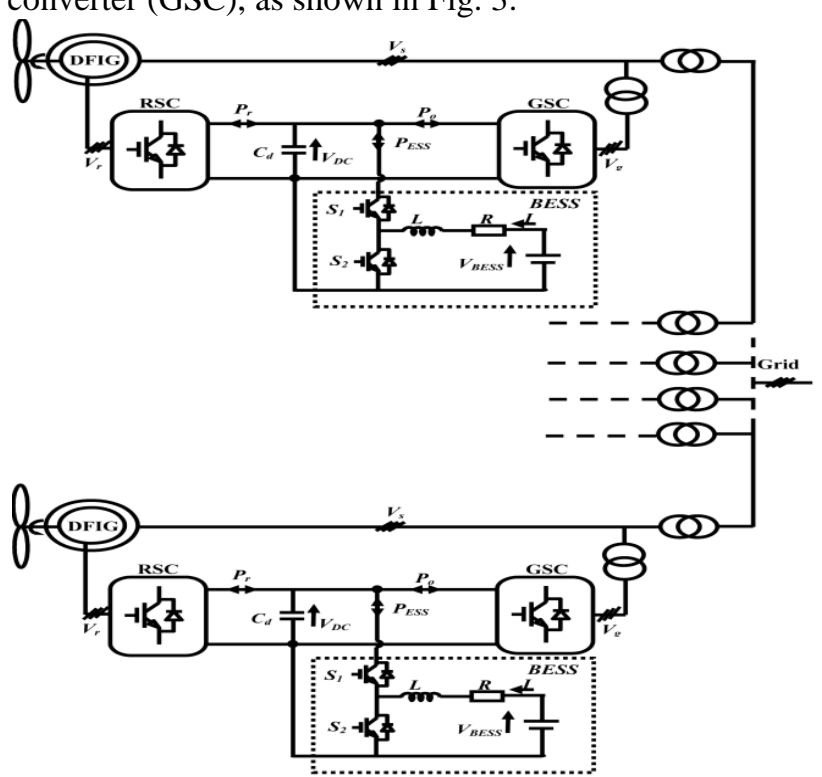

Fig.3. Scheme of the proposed control

\section{A. PI-Controller-Based DC Voltage Controller}

The proposed scheme is controlled by the two-loop PI control design, i.e., one inner loop controlling the current $\mathrm{I}_{\mathrm{GSC}}$ and one outer loop controlling dc voltage $\mathrm{V}_{\mathrm{DC}}$.

For outer dc voltage loop can be designed as:

$$
I *_{G S C}=C \cdot k_{p L}\left(V_{d c}-V{ }_{d c}\right)+C \cdot k_{i L} \int\left(V_{d c}-V_{d c}^{*}\right)
$$

Where $k_{p L}$ and $k_{i L}$ are the proportional and integral gains, respectively. The dc circuit can be expressed using the current balancing equation as:

$$
I_{R S C}=I_{G S C}+I_{E S S}+C \frac{d V_{d c}}{d t}
$$

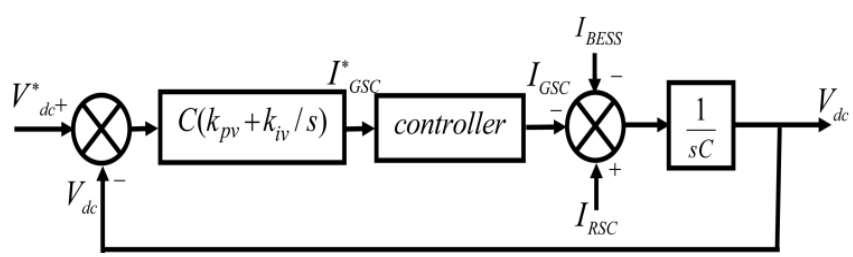

Fig.4. Block diagram of Buck converter

\section{Simulations and Discussion}

\section{A. Simulations}

To achieve the results of our theoretical study, the model block of the Figure 3 has been implemented in the MATLAB/Simulink. The model contains six Wind Turbine based DFIG connected to the grid. Each wind turbine has the same proposed control. The fault occurs on the power grid. The default start at $t_{i}=0.8 \mathrm{~s}$ and finish at $t_{\mathrm{f}}=1.4 \mathrm{~s}$, the default affects all three phases and causes a fall of voltage of $60 \%$ of the rated voltage shown in figure 6 , wind velocity is considered randomly as shown in figure 5. The parameters used for the simulation are given in the Table 1.

TABLE I.

SPeCifiCATIONS Used For The Simulation

\begin{tabular}{|c|c|c|}
\hline Components & Part name & $\begin{array}{l}\text { Rating } \\
\text { values }\end{array}$ \\
\hline$D F I G s$ & Rated Generator Power & $6 \times 1,5 \mathrm{MW}$ \\
\hline$V_{s}$ & $\begin{array}{c}\text { Rated Terminal stator } \\
\text { voltage }\end{array}$ & $690 \mathrm{~V}$ \\
\hline$f$ & Rated frequency & $50 \mathrm{~Hz}$ \\
\hline$R_{s}$ & Stator Resistance & $0.0048 \mathrm{~m} \Omega$ \\
\hline$L_{s}$ & Stator leakage inductance & $0.1386 \mathrm{mH}$ \\
\hline$R_{r}$ & Rotor Resistance & $0.00549 \mathrm{~m} \Omega$ \\
\hline$L_{r}$ & $\begin{array}{c}\text { Rotor leakage } \\
\text { inductance }\end{array}$ & $0.1493 \mathrm{mH}$ \\
\hline$V_{d c}$ & Rated DC-link Voltage & $1150 \mathrm{~V}$ \\
\hline$C_{d}$ & Input Capacitance & $10 \mu \mathrm{F}$ \\
\hline$C_{d}$ & $\begin{array}{c}\text { Capacitance of buck } \\
\text { converter }\end{array}$ & $5 \mu \mathrm{F}$ \\
\hline$L_{r}$ & Inductance of buck converter & $3.9 \mathrm{mH}$ \\
\hline$f_{s}$ & Switching Frequency & $50 \mathrm{KHZ}$ \\
\hline$K p$ & Proportional coefficient & 62,8 \\
\hline$K i$ & Integral coefficient & 987 \\
\hline & &
\end{tabular}




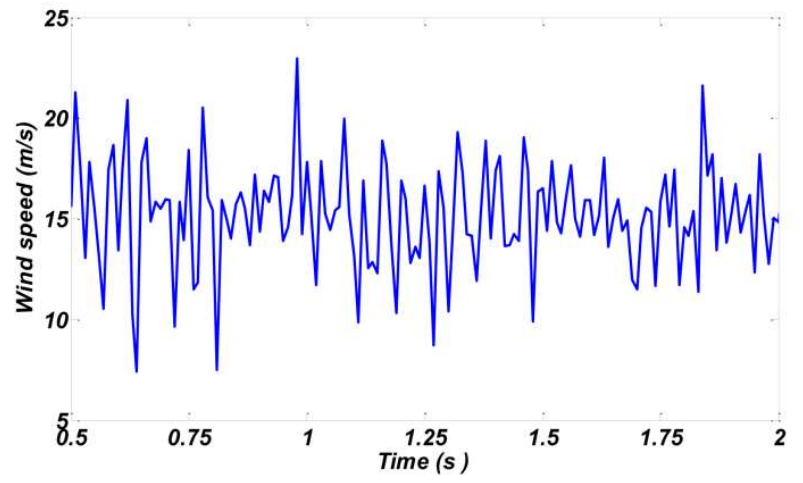

Fig.5 Wind speed evolution

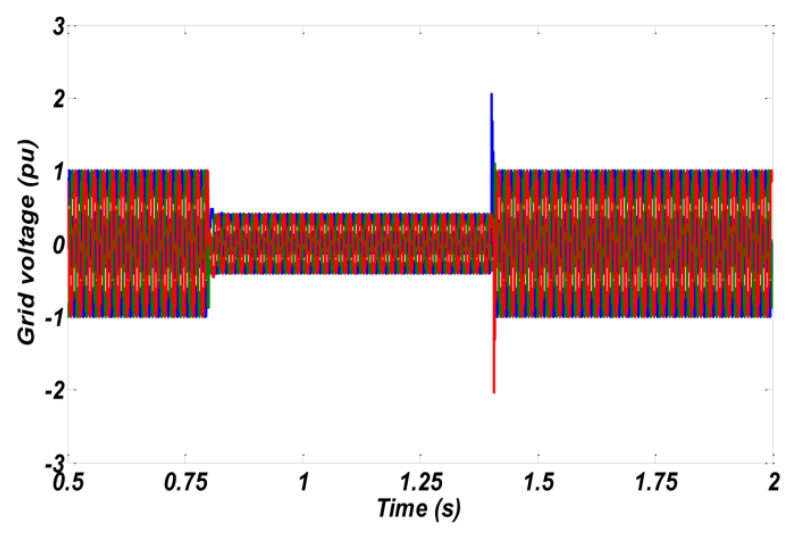

Fig.6. Grid Voltage

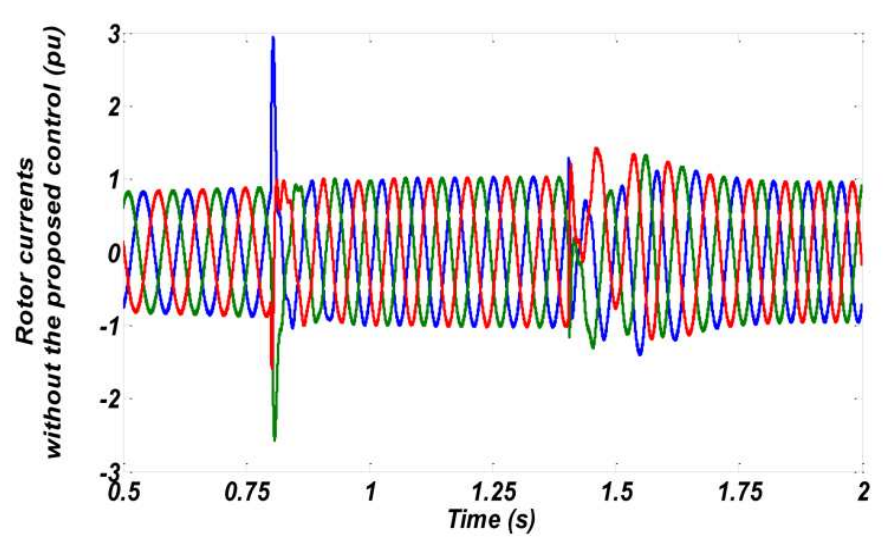

Fig.7. Rotor current without the proposed control

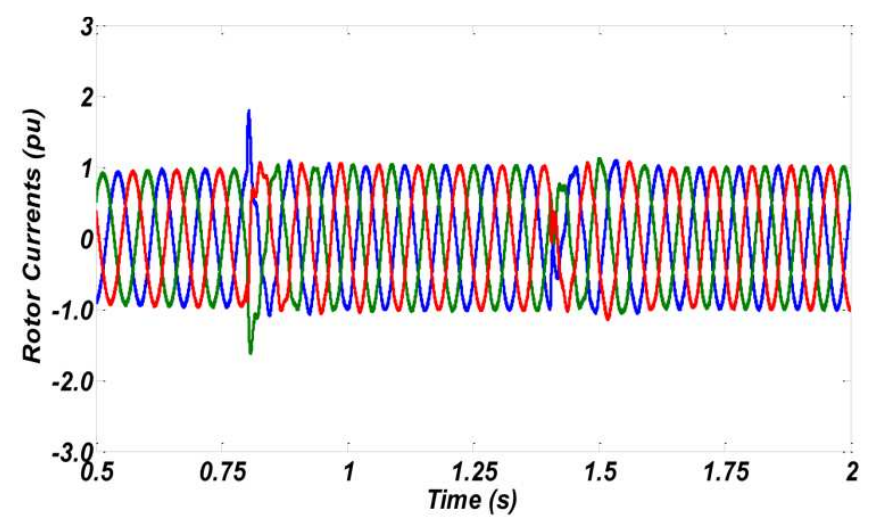

Fig.8. Rotor current with the proposed control

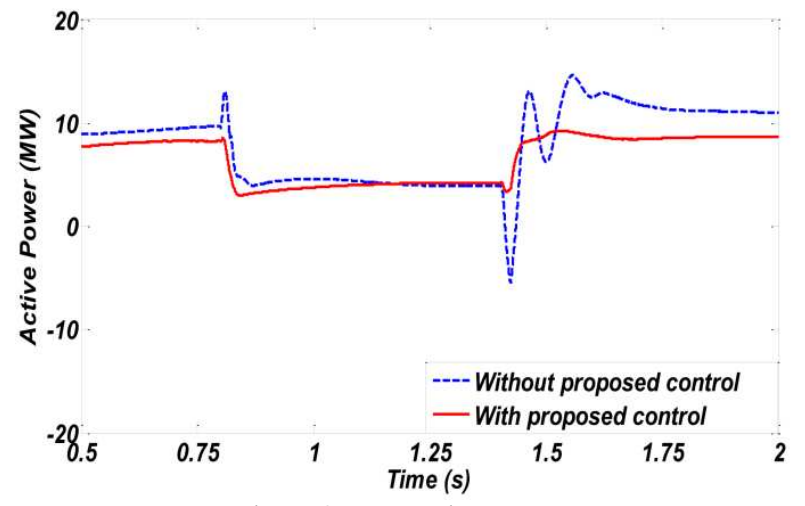

Fig.9. Output active power

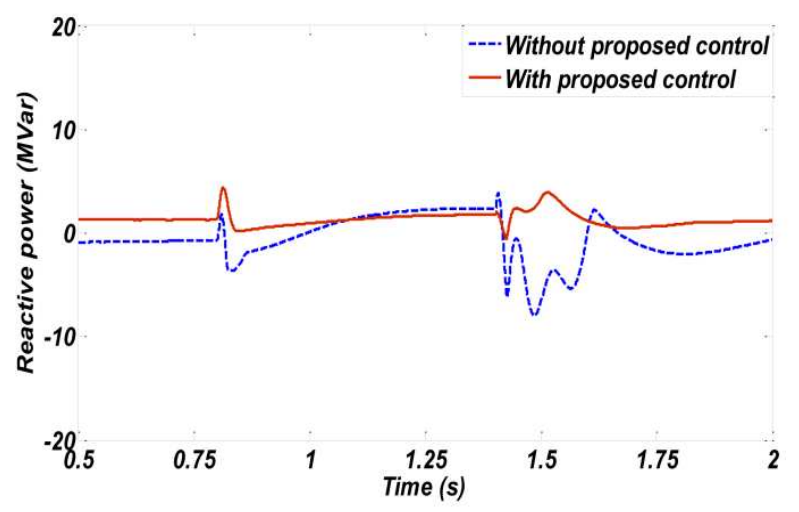

Fig.10. Output reactive power

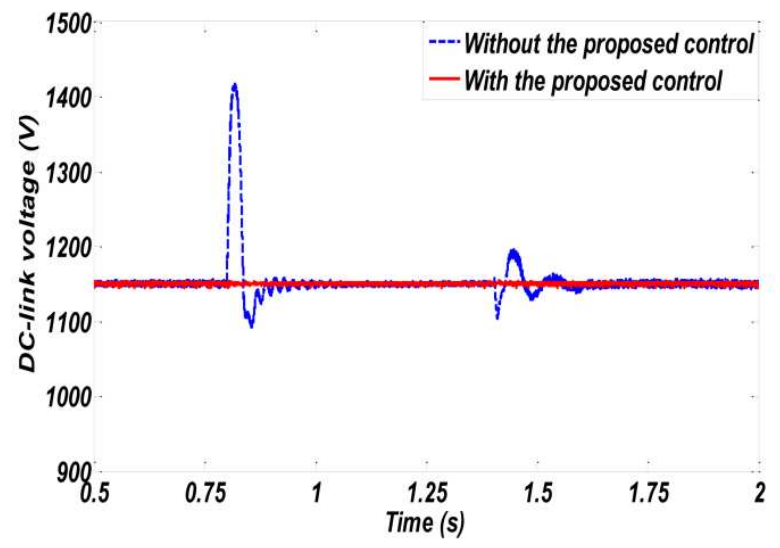

Fig.11. DC-link voltage

\section{B. Discussion:}

Fig.7 represents the rotor current of DFIG with the conventional control under faults. Fig. 8 show the reduced peak of the rotor current with the proposed control. Active power injected to electrical grid is shown in fig. 9, the fluctuation is smoothed precisely between $\mathrm{t}_{\mathrm{i}}=0.8 \mathrm{~s}$ and $\mathrm{t}_{\mathrm{f}}=1.4 \mathrm{~s}$

Fig.10 represents the reactive power of DFIG with the conventional control and with the proposed control, We can see that it is kept around zero. Fig.11. shows the fluctuations of the DC bus voltage with conventional control which could reach $1425 \mathrm{~V}$; this may destroy the power converters and destabilizes the dynamic performance of DFIG. With the proposed control the DC bus voltage become more stable with slight fluctuations compared to overshoot of the DC bus voltage observed with conventional control. 


\section{Conclusion}

In this paper, a control strategy for DFIG system has been proposed to enhance low voltage ride through capability. The proposed control strategy introduces a battery energy storage system for protecting the DC link and the two converters GSC and RSC.

Comparing with the traditional control strategy, the proposed structure gives a better transient behavior for DFIG based system. Simulation results, obtained with an insignificant additional computation time, confirmed the efficacy of the proposed control strategy with two main results: the reduction of the peak of the rotor currents and smoothing the fluctuation of the dc-link voltage during symmetrical grid fault.

\section{Acknowledgement}

The research developed in this paper is performed in the GREAH Laboratory of the University of Le Havre and is funded by BATTUTA Project in the frame of the European ERASMUS MUNDUS program.

\section{References}

[1] J. Liang, W. Qiao and R.G Harley, "Feed-Forward Transient Current Control for Low-Voltage Ride-Through Enhancement of DFIG Wind Turbines" IEEE Trans. on energy Conversion, vol. 25, no. 3, pp.836-843, September 2010.

[2] S. Hu, X. Lin, Y. Kang, and X. Zou, "An improved lowvoltage ride-through control strategy of doubly fed induction generator during grid faults" IEEE Transactions Power Electron., Vol. 26, no. 12,pp. 3653-3665, December 2011.

[3] E.Tremblay, S.Atayde and A.Chandra, "Comparative Study of Control Strategies for the Doubly Fed Induction Generator in Wind Energy Conversion Systems: A DSPBased Implementation Approach", IEEE Trans. Sustainable energy, vol. 2, no. 3, pp. 288-299, july 2011.

[4] T. Sun, Z. Chen and F. Blaabjerg, "Voltage recovery of grid-connected wind turbines after a short-circuit fault," Proceedings of the $29^{\text {th }}$ Annual Conference of the IEEE Industrial Electronics Society (IECON '03), vol. 3, Nov. 2-6, 2003 , pp. $2723-2728$.
[5] A. O. Ibrahim, T. H. Nguyen, D.C. Lee and S.C Kim, "A Fault Ride-Through Technique of DFIG Wind Turbine Systems Using Dynamic Voltage Restorers" IEEE Trans. On Energy Conversion, Vol. 26, no. 3: pp.871-882, September 2011

[6] H.Huang and C. Y. Chung, "Coordinated Damping Control Design for DFIG-Based Wind Generation Considering Power Output Variation" IEEE Trans. Power Systems, vol. 27, no. 4,pp.1916-1925, November 2012.

[7] J. Morren and S. W. H. de Hann, "Ride through of wind turbines with doubly-fed induction generator during a voltage dip," IEEE Trans. Energy Convers., vol. 20, no. 2, pp. 435-441, Jun. 2005.

[8] T. Riouch and R. EL-Bachtiri, "New control strategy to reduce the fluctuations of the $\mathrm{dc}$ bus of a wind turbine using the DFIG", Journal of Theoretical and Applied Information Technology, Vol. 40,no.2, June 2012.

[9] I. Erlich, J. Kretschmann, J. Fortmann, S. MuellerEngelhardt, and H. Wrede, "Modeling of wind turbines based on doubly-fed induction generators for power system stability studies," IEEE Trans. Power Syst., vol. 22, no. 3, pp. 909-919, Aug. 2007.

[10] I. Erlich, H. Wrede, and C. Feltes, "Dynamic behavior of DFIG-based wind turbines during grid faults," presented at the Power Convers. Conf., Nagoya, Japan, April 2-5, 2007.

[11] T. Riouch and R. EL-BACHTIRI "Comparative Study of Fuzzy Logic Controller and Sliding Mode for Enhancing the Behavior of the DFIG Under Fault" in Proc. IEEE (ICMCS'14) April 2014.

[12] T. Riouch and R. EL-BACHTIRI "Improvement LowVoltage Ride-Through Control of DFIG During Grid Faults" in Proc. IEEE (ICMCS'14) April 2014.

[13] J. Lopez, P. Sanchis, X. Roboam, and L. Marroyo, "Dynamic behavior of the doubly-fed induction generator during three-phase voltage dips,"IEEE Trans Energy Convers., vol. 22, no. 3, pp. 709-717, Sep. 2007.

[14] S. Xiao, G. Yang , H. Zhou and H. Geng, "A LVRT Control Strategy based on Flux Linkage Tracking for DFIG-based WECS" IEEE Trans. Ind. Electron., vol. 60, no. 7 , pp.2820 -2832, July 2013.

[15] J. Lopez , P. Sanchis , X. Roboam and L. Marroyo "Dynamic behavior of the doublyfed induction generator during three-phase voltage dips", IEEE Trans. Energy Convers., vol. 22, no. 3, pp.709-717, Septembre 2007.

[16] T. Riouch and R. E. Bachtiri "Robust control of the active and reactive power exchanged with the rotor of the DFIG and the grid" WSEAS Trans.on Environment and Development, Vol. 9, no. 1, pp. 35-45, , January 2013. 